\section{The effect of salicylates on insulin sensitivity}

Insulin resistance, a characteristic feature of type 2 diabetes, is associated with central obesity, hypertension, dyslipidemia, and cardiovascular disease (and death) (1). The mechanism of insulin resistance is complex and largely unknown. Both in animals and in humans, however, insulin resistance can be induced by lipid infusion. In a recent issue of the JCI, Kim and colleagues presented new data on the mechanisms responsible for the induction of insulin resistance by lipids. In an elegant set of experiments, they show that activation of IKK- $\beta$ is important in fat-induced insulin (2). High-dose salicylate prevents the fatinduced defects in insulin signaling. Based on these findings, the authors suggest that "salicylates represent a potentially novel class of therapeutic agents for type 2 diabetes" (2).

Although the carefully performed study by Kim et al. provides new insight into the mechanisms of fatinduced insulin resistance, we would like to caution against the preliminary conclusion concerning beneficial effects of salicylates on insulin resistance. First of all, in contrast to the findings of Kim et al. in the triglyceride (TG) infusion model in the rat, earlier studies in human volunteers using hyperglycemic clamp techniques reported increased insulin resistance by salicylate compounds $(3,4)$. These findings suggest that the effects of salicylates may depend on the experimental model, and possibly on the species studied.

There are also strong theoretical arguments that salicylates have deleterious effects on insulin resistance. Similar to TGs (or fatty acids), the proinflammatory cytokine TNF- $\alpha$ synthesized by adipocytes is a central factor in the pathogenesis of insulin resistance (5). As underlined also by Kim et al., there is significant overlap between the intracellular events induced by fatty acids and TNF in insulin-sensitive tissues: both activate IKK- $\beta$ and decrease IRS- 1 tyrosine phosphorylation, and both increase intracellular ceramide concentrations,

Figure 1 which leads to inhibition of Akt/protein kinase $\mathrm{B}$ activation and impaired GLUT-4 translocation (these relationships are outlined in Figure 1) (6-8). The effects of salicylates on TNFinduced insulin resistance are completely opposite to those reported by Kim and colleagues on fat-induced insulin resistance. TNF induces the synthesis of prostaglandins (PGs), which function as a negative feedback mechanism by inhibiting the upstream TNF production (9). We and others have shown in healthy volunteers that administration of aspirin or indomethacin, both strong inhibitors of PG synthesis, enhances TNF production capacity at least twofold $(10,11)$, which can negatively affect insulin sensitivity. In addition, PGs stimulate synthesis of leptin, an adipocytokine known to decrease insulin resistance through improvement of IRS-1-associated phosphatidylinositol (PI) 3-kinase activity
$(12,13)$. Although not yet experimentally tested, inhibition of PG synthesis by salicylate compounds may also negatively influence insulin sensitivity by inhibition of leptin release. Thus, aspirin could increase insulin resistance through at least two mechanisms mediated by the inhibition of PG synthesis, namely the upregulation of TNF synthesis and the inhibition of leptin release (Figure 1 ). There are other important endogenous factors modulating the resistance to insulin: adiponectin reverses insulin resistance, possibly in part by inhibition of TNF synthesis, whereas resistin impairs glucose tolerance and insulin action $(12,14)$. The influence of salicylates on the modulation of these proteins is not known.

In conclusion, the influence of salicylate compounds on insulin sensitivity is multifactorial and involves both beneficial and deleterious effects. This should not preclude patients from taking low-dose aspirin to prevent cardiovascular disease (15), but more basal and clinical studies

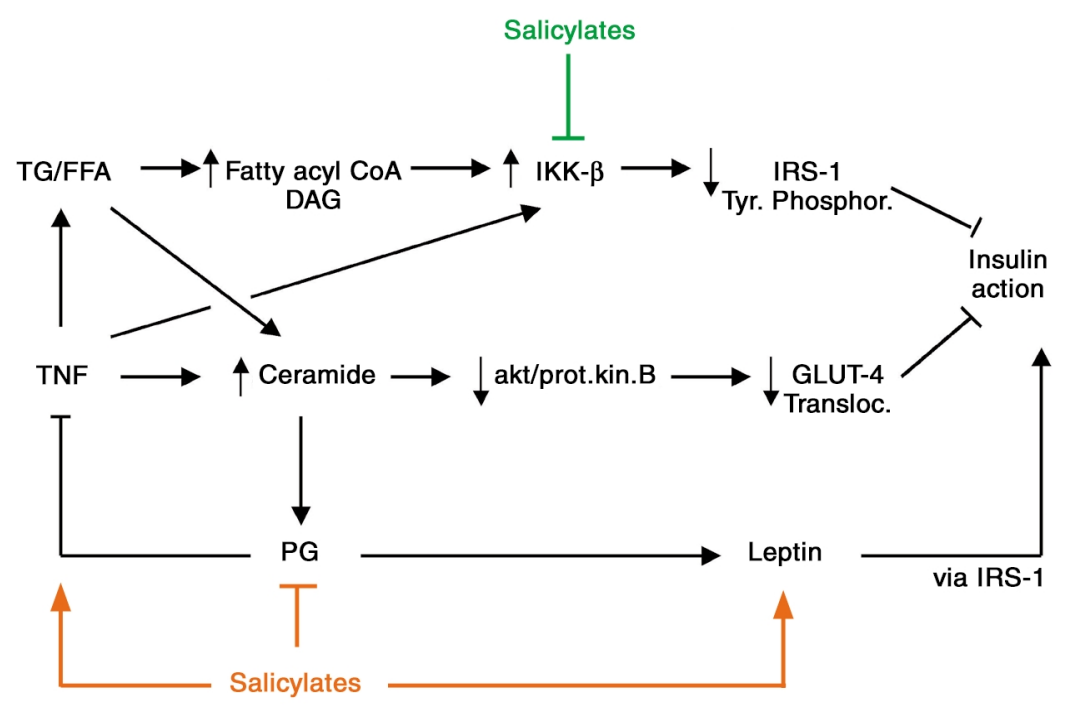

The effects of salicylates on insulin resistance. There is significant overlap between the intracellular events induced by TGs (or FFAs) and TNF regarding the mechanisms of insulin resistance. Both stimuli activate IKK- $\beta$ and decrease insulin-induced tyrosine phosphorylation of IRS-1; both increase intracellular ceramide concentrations, which leads to inhibition of Akt/protein kinase B activation and inhibition of GLUT-4 translocation. These effects induce a state of insulin resistance. The effects of salicylate compounds on these pathways may be divergent. That is, they may improve insulin resistance by blocking the activation of IKK- $\beta$ (top), or they may worsen insulin resistance by inhibiting PG synthesis and thus potentiating TNF release (bottom). In addition, inhibition of PG will decrease synthesis of leptin, which is known to improve insulin sensitivity by stimulating IRS-1-associated PI 3-kinase activity. The beneficial effect of leptin on insulin action is thus decreased (bottom). 
are needed before recommending higher dosages of salicylates for the treatment of type 2 diabetes itself.

\section{Mihai G. Netea, ${ }^{1}$ Cees J. Tack, ${ }^{1}$ Paetrick M. Netten, ${ }^{2}$ \\ Jos A. Lutterman, ${ }^{1}$ and Jos W.M. Van der Meer ${ }^{1}$ \\ ${ }^{1}$ Department of Medicine, University Medical Center St. Radboud, Nijmegen, The Netherlands \\ ${ }^{2}$ Department of Internal Medicine, Bosch Medicentrum, 's-Hertogenbosch, The Netherlands}

Address correspondence to: Mihai G. Netea, Department of Medicine (541),

University Medical Center St. Radboud, Geert Grooteplein 8, PO Box 9101, 6500 HB Nijmegen, The Netherlands. Phone: 31-24-3614652; Fax: 31-24-3541734; E-mail: M.Netea@aig.azn.nl.

1. Reaven, G.M. 1993. Role of insulin resistance in human disease (syndrome X): an expanded definition. Annu. Rev. Med. 44:121-131.

2. Kim, J.K., et al. 2001. Prevention of fat-induced insulin resistance by salicylate. J. Clin. Invest. 108:437-446.

3. Newman, W.P., and Brodows, R.G. 1983. Aspirin causes tissue insensitivity to insulin in normal man. J. Clin. Endocrinol. Metab. 57:1102-1106.

4. Giugliano, D., Sacca, L., Scognamiglio, G., Ungaro, B., and Torella, R. 1982. Influence of acetylsalicylic acid on glucose turnover in normal man. Diabetes Metab. 8:279-282.

5. Uysal, K.T., Wiesbrock, S.M., Marino, M.W., and Hotamisligil, G.S. 1997. Protection from obesityinduced insulin resistance in mice lacking TNF$\alpha$ function. Nature. 389:610-614.

6. Shulman, G.I. 2000. Cellular mechanisms of insulin resistance. J. Clin. Invest. 106:171-176.

7. Hotamisligil, G.S. 1999. Mechanisms of TNFalpha-induced insulin resistance. Exp. Clin. Endocrinol. Diabetes. 107:119-125.

8. Kanety, H., Hemi, R., Papa, M.Z., and Karasik, A 1996. Sphingomyelinase and ceramide suppress insulin-induced tyrosine phosphorylation of the insulin receptor substrate-1. J. Biol. Chem. 271:9895-9897.

9. Renz, H., Gong, J.-H., Schmidt, A., Nain, M., and Gemsa, D. 1988. Release of tumor necrosis factor$\alpha$ from macrophages. Enhancement and suppression are dose-dependently regulated by prostaglandin E2 and cyclic nucleotides. $J$. Immunol. 141:2388-2393.

10. Endres, S., Whitaker, R.E.D., Ghorbani, R., Meydani, S.N., and Dinarello, C.A. 1996. Oral aspirin and ibuprofen increase cytokine-induced synthesis of IL- $1 \beta$ and of tumour necrosis factor- $\alpha$ ex vivo. Immunology. 87:264-270.

11. Netea, M.G., Puren, A.J., and Dinarello, C.A. 2000 A short course of oral aspirin increases IL-18 induced interferon-gamma production in wholeblood cultures. Eur. Cytokine Netw. 11:379-382.

12. Yamauchi, T., et al. 2001. The fat-derived hormone adiponectin reverses insulin resistance associated with both lipoatrophy and obesity. Nat. Med. 7:941-946.

13. Kim, Y.-B., Uotani, S., Pierroz, D.D., Flier, J.S., and Kahn, B.B. 2000. In vivo administration of leptin activates signal transduction directly in insulinsensitive tissues: overlapping but distinct pathways from insulin. Endocrinology. 141:2328-2339.

14. Steppan, C.M., et al. 2001. The hormone resistin links obesity to diabetes. Nature. 409:307-312.

15. Rolka, D.B., Fagot-Campagna, A., and Venkat Narayan, K.M. 2001. Aspirin use among adults with diabetes. Estimates from the Third National Health and Nutrition Examination. Diabetes Care. 24:197-201.

Kim et al. reply - We would like to thank Netea et al. for their thoughtful comments regarding our article (1). First of all, we would like to emphasize that we are not advocating the use of high-dose aspirin for the treatment of type 2 diabetes. In fact, we strongly recommend against it in view of aspirin's potential long-term toxicities at high doses. Our studies used high-dose aspirin as a pharmacological tool to identify IKK- $\beta$ as a potentially novel therapeutic target for type 2 diabetes. This hypothesis, developed by Yuan et al. (2), led to our finding that $I k k-\beta^{-/+}$mice were protected from obesity-and diet-induced insulin resistance (2) as well as following 5-hour lipid infusion (1). Because aspirin is a weak inhibitor of IKK- $\beta$, high doses of the drug restore insulin sensitivity in each of these models of insulin resistance.

We are aware of the previous studies that have shown that aspirin therapy actually causes insulin resistance (3-5). We believe the major reason for the discrepancy is not due to species differences as suggested by Netea et al. but rather the lower dose and duration of salicylate therapy used in these human studies. Even older clinical trials clearly showed hypoglycemic effects of high doses (4-10 g/day) of aspirin and salicylate that occur progressively over 1 to 2 or 3 weeks (6). Using corresponding therapeutic regimens, we saw beneficial effects in rodents $(1,2)$ and, in more recent studies by our group, in humans (7). Highdose salicylate treatment (about 7 $\mathrm{g} /$ day for 2 weeks) was very successful in lowering fasting and postprandial hyperglycemia in patients with type 2 diabetes, which could partly be attributed to increased peripheral insulin sensitivity as assessed by a hyperinsulinemic-euglycemic clamp (7).

In summary, we believe that our data (1) support the hypothesis that fat induces insulin resistance through activation of a serine/threonine kinase cascade leading to decreased IRS1/IRS-2-associated phosphatidylinositol 3-kinase activity in muscle and liver $(2,8)$, and that IKK- $\beta$, and the steps leading to its activation, are potential novel therapeutic targets for type 2 diabetes mellitus.

\section{Jason K. Kim, Steven E. Shoelson, and Gerald I. Shulman}

1. Kim, J.K., et al. 2001. Prevention of fat-induced insulin resistance by salicylate. J. Clin. Invest. 108:437-446.

2. Yuan, M. et al. 2001. Reversal of obesity- and dietinduced insulin resistance with salicylates or targeted disruption of Ikk- $\beta$ Science. 293:1673-1677.

3. Newman, W.P., and Brodows, R.G. 1983. Aspirin causes tissue insensitivity to insulin in normal man. J. Clin. Endocrinol. Metab. 57:1102-1106.

4. Giugliano, D., Sacca, L., Scognamiglio, G., Ungaro, B., and Torella, R. 1982. Influence of acetylsalicylic acid on glucose turnover in normal man. Diabete Metab. 8:279-282.

5. Bratusch-Marrain, P.R., Vierhapper, H., Komjati, M., and Waldhausl, W.K. 1985. Acetyl-salicylic acid impairs insulin-mediated glucose utilization and reduces insulin clearance in healthy and noninsulin-dependent diabetic man. Diabetologia. 28:671-676.

6. Reid, J., Macdougall, A.I., and Andrews, M.M. 1957. On the efficacy of salicylate in treating diabetes mellitus. Br. Med. J. 2:1071-1075.

7. Hundal, R.S., et al. 2001. Potential for a novel class of insulin sensitizing agents by inhibition of IKK- $\beta$ activity. Diabetes. 50:A117.

8. Shulman, G.I. 2000. Cellular mechanisms of insulin resistance. J. Clin. Invest. 106:171-176. 